PONTIFÍCIA UNIVERSIDADE CATÓLICA DO RIO DE JANEIRO

\title{
Liderança feminina: como os consumidores percebem mulheres em posições de liderança no setor bancário.
}

Nathalia Rodrigues Pin

Trabalho de Conclusão de Curso

CENTRO DE CIÊNCIAS SOCIAIS - CCS

DEPARTAMENTO DE ADMINISTRAÇÃO

Graduação em Administração de Empresas 


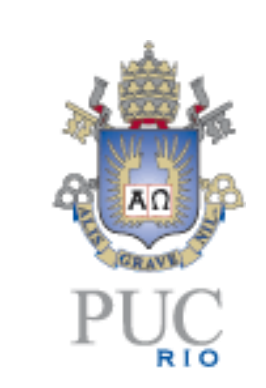

Nathalia Pin

\section{Liderança feminina: como os consumidores percebem mulheres em posições de liderança no setor bancário.}

Trabalho de Conclusão de Curso

Trabalho de Conclusão de Curso, apresentado ao programa de graduação em Administração da PUC-Rio como requisito parcial para a obtenção do titulo de graduação em Administração.

Orientador(a) : Daniel Kamlot.

Rio de Janeiro, Novembro de 2019. 


\section{Agradecimentos}

A Deus por ter me abençoado durante toda minha trajetória e me dado forças para nunca desistir dos meus objetivos.

Aos meus pais, Renato Pin e Jaciara Rodrigues, que sempre acreditaram nos meus sonhos e nunca mediram esforços para realizá-los. Sem vocês nada disso seria possível.

Ao meu namorado, João Pedro, por estar ao meu lado me apoiando em todos os momentos.

Aos meus amigos por todo companheirismo e irmandade durante todos esses anos.

Ao meu orientador, Daniel Kamlot, por todo o apoio dado durante a construção deste trabalho e por todos os conselhos.

À PUC-Rio, por todas as oportunidades de crescimento acadêmico, pessoal e profissional. 


\section{Resumo}

Rodrigues, Nathalia Pin. Liderança feminina: como os consumidores percebem mulheres em posições de liderança no setor bancário. Rio de Janeiro, 2019. Número de páginas p. 48. Trabalho de Conclusão de Curso - Departamento de Administração. Pontifícia Universidade Católica do Rio de Janeiro.

No Brasil, as mulheres vêm ocupando cada vez mais seu espaço na sociedade e no mercado de trabalho. Todavia, apesar dos inúmeros avanços conquistados, a igualdade de gênero ainda está longe de ser alcançada. Vale ressaltar que, mesmo com o passar dos anos, ocorreram diversas mudanças culturais e por consequência quebras de estereótipos, porém as funções, cargos e salários atribuídos às mulheres encontram-se em defasagem quando comparado aos homens. Com o mercado bancário cada vez mais competitivo, na medida em que se observa o aumento de empresas que nele atuam, e com a sociedade cada vez mais inclusiva, torna-se imprescindível se posicionar frente às causas sociais e analisar o comportamento do consumidor quanto às mesmas. Diante deste contexto, este trabalho analisa, por meio de uma pesquisa descritiva com base em dois questionários online, como a distinção de gênero em posições superiores no mercado bancário altera a percepção dos consumidores. Os resultados foram encontrados através de análises quantitativas onde foi possível concluir que a distinção de gênero é de fato percebida pelo consumidor bancário. Além disso, foi constatado que os respondentes possuem em sua percepção estereótipos enraizados de maneira sutil, uma vez que no geral acabaram por preferir o sexo masculino.

Palavras-chave:

Liderança feminina; setor bancário; discriminação de gênero; percepção do consumidor. 


\section{Abstract}

Pin, Nathalia Rodrigues. Female leadership: consumer perceptions with women in leading positions in the banking sector. Rio de Janeiro, 2019. Number of pages $p$. 48. Final Course Work - Administration Departament. Pontifícia Universidade Católica do Rio de Janeiro.

In Brazil, women have been conquering their space in society and in the labor market. However, despite the numerous advances made, gender equality is still far from being achieved. It is worth mentioning that, even over the years, where there have been several cultural changes and consequently a break of stereotypes, the functions, positions and salaries attributed to women are lagging when compared to men. With the increasingly competitive banking market, as the growth of companies operating in it is observed, and with the increasingly inclusive society, it is essential to take a stand for social causes and analyze consumer behavior. Given this context, this paper analyzes, through a descriptive research based on two online questionnaires, how gender distinction in higher positions in the banking market changes the perception of consumers. The results were found through quantitative analysis where it was possible to conclude that consumers actually perceive the gender distinction. In addition, it was found that respondents have subtle stereotypes in their perception, since they generally preferred males.

Key-words:

Female leadership; banking sector; gender discrimination; consumer perception. 


\section{Sumário}

1. Introdução 9

$\begin{array}{ll}1.1 \text { Objetivo final } & 10\end{array}$

1.2 Delimitação do estudo 10

1.3 Relevância do estudo 11

2. Referencial Teórico 12

2.1 A mulher e o mercado de trabalho no Brasil 12

2.1.1 Preconceito e estereótipos 13

2.1.2 Sexismo 14

2.2 A mulher no setor bancário $\quad 15$

2.3 Liderança feminina 17

2.4 Percepção do consumidor 19

2.5 Posicionamento 20

3. Metodologia 22

3.1 Tipo de pesquisa 22

3.2 Universo e amostra 22

3.3 Procedimentos e Instrumentos de Coleta de Dados 23

3.4 Tratamento dos dados 24

3.5 Limitações do método $\quad 24$

4. Análise dos resultados 25

4.1 Descrição e análise do perfil dos respondentes 25

4.2 Análise da percepção dos consumidores 28

5. Conclusão 37

6. Referências Bibliográficas 39 


\section{Índice de Quadros}

Quadro 1- Média referente aos resultados da questão 7- Questionário 1 ...................... 29

Quadro 2- - Média referente aos resultados da questão 7 - Questionário 2 .................. 29

\section{Índice de Tabelas}

Tabela 1- Notas dos bancos no tema Igualdade de gênero ..................................... 16

Tabela 2- Distribuição por setor de atividade econômica ............................................ 19

Tabela 3 - Resultado referente a "Q5: De qual(is) banco(s) abaixo você é consumidor?" -

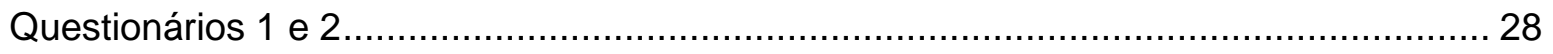

Tabela 4- Resultado referente a "Q7: Qual é a responsabilidade do profissional pelos resultados da organização?" - Questionários 1 e 2 ................................................... 29

Tabela 5- Resultado referente a "Q10: Postura dos diretores" Questionários 1 e 2........ 31

\section{Índice de Gráficos}

Gráfico 1- Resultado referente a "Q1: Qual a sua faixa etária?” - Questionário 1 ........... 26

Gráfico 2- Resultado referente a "Q1: Qual a sua faixa etária?” - Questionário 2 ........... 26

Gráfico 3- Resultado referente a "Q2: Qual o seu gênero?” - Questionário 1 ................. 27

Gráfico 4- Resultado referente a "Q2: Qual o seu gênero?” - Questionário 2 ................ 27

Gráfico 5- Resultado referente a "Q9:A diretora sabe avaliar as consequências de suas

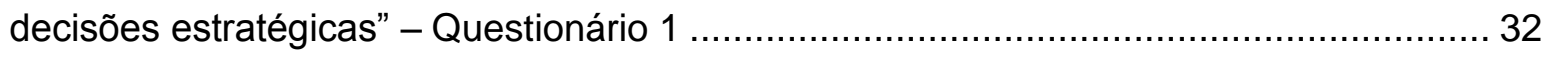


Gráfico 6- Resultado referente a "Q9: O diretor sabe avaliar as consequências de suas decisões estratégicas"- Questionário 2 ….......................................................... 32

Gráfico 7- Resultado referente a "Q11: No dia a dia dessa profissional, ela encontra dificuldades"- Questionário 1 ............................................................................. 33

Gráfico 8- Resultado referente a "Q11: No dia a dia desse profissional, ele encontra

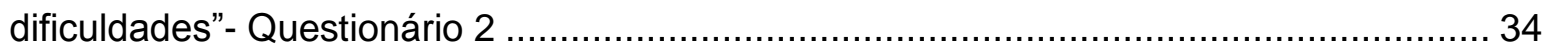

Gráfico 9- Resultado referente a "Q13: Sendo um homem ao ocupar o mesmo cargo, o

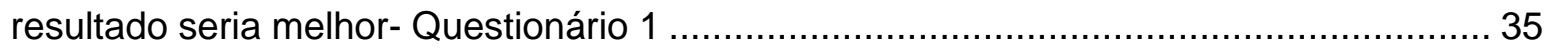

Gráfico 10- Resultado referente a "Q13: Sendo uma mulher ao ocupar o mesmo cargo, o resultado seria melhor"- Questionário 2 36 


\section{Introdução}

Desde a Revolução Industrial no século $\mathrm{XVI}$, as mulheres vêm lutando incansavelmente contra a discriminação de gênero. Por anos suas funções se limitaram a afazeres domésticos, responsabilidades conjugais, familiares e imposições sociais. A inserção da mulher no mercado de trabalho não somente foi um grande avanço, mas sim a propagação de um movimento social que surgiu frente a uma grande necessidade: a emancipação da figura feminina.

É de suma importância analisar as informações disponíveis para assim compreender o cenário atual e suas previsões futuras. Segundo o Ministério do Trabalho no Brasil (2016), o crescimento da ocupação feminina em postos formais de trabalho ocorreu em aproximadamente 4\% de 2007 até 2016. No entanto, os números não estão de acordo com o percentual da população feminina no Brasil, que de acordo com o Instituto Brasileiro de Geografia e Estatística (IBGE, 2018), já passa de metade da população $(51,03 \%)$. Além disso, vale ressaltar que, conforme a Organização Internacional do Trabalho (OIT, 2018), as mulheres são menos propensas a participarem do mercado de trabalho do que os homens e têm mais chances de estarem desempregadas na maior parte dos países do mundo.

Nota-se que apesar dos inúmeros avanços conquistados e dos compromissos assumidos, a igualdade de gênero ainda está longe de ser alcançada. A discriminação feminina ocorre mundialmente e não de maneira ostensiva, mas sim de forma sutil (VILAS-BOAS, 2003). De fato, algumas questões poderiam ser resolvidas por meio de leis que determinariam direitos iguais, por exemplo, a diferença salarial. Por outro lado, o acesso a oportunidades, a pressão da sociedade e a percepção certas vezes discriminativa dos consumidores são mudanças culturais e sociais significativas que levam tempo.

A sociedade relaciona a imagem feminina a valores estabelecidos socialmente que remetem a beleza, fragilidade e submissão principalmente em setores em que se observa 
uma predominância masculina, como por exemplo no mercado bancário. Tal fato decorre de um contexto histórico de padrões estabelecidos; apesar disso, mesmo que de maneira lenta, a mulher vem ocupando cada vez mais seu espaço. Com o passar dos anos, ocorreram diversas mudanças culturais e por consequência quebras de estereótipos, obrigando as empresas a administrarem em um ambiente mais flexível e a entender como o consumidor vem reagindo a isso. As organizações, dessa forma, vêm sendo provocadas a buscar estratégias a fim de obter vantagem competitiva e de tornarem-se cada vez mais ágeis e adaptáveis às constantes mudanças.

De fato, uma empresa que adota a heterogeneidade de gêneros provavelmente terá uma visão mais ampla, a qual irá enxergar e lidar com as diversas variáveis do mercado de maneira eficaz. Segundo Kamlot et al. (2011), grandes instituições, principalmente as instituições financeiras, vêm passando por inúmeras transformações nos últimos anos, com processos de descobertas e adaptações. E o consumidor altera seu comportamento de acordo com tais mudanças percebidas.

Sob essa ótica, o presente trabalho se propõe a responder a seguinte questão: como a distinção de gênero em posições superiores no mercado bancário altera a percepção dos consumidores e qual o impacto sobre as organizações?

\subsection{Objetivo final}

Frente às destoantes expectativas de gênero geradas pela desigualdade no mercado de trabalho atualmente, o estudo tem como objetivo avaliar a percepção dos consumidores do mercado bancário sobre mulheres em cargos de liderança e identificar oportunidades e ameaças decorrentes dessa percepção.

\subsection{Delimitação do estudo}

O estudo delimita-se a analisar a percepção dos consumidores de ambos os sexos do mercado bancário do Brasil, por ser o de maior representatividade no setor financeiro e compreender um contexto masculino competitivo e agressivo. Optou-se por focar nas empresas que possuem maior participação no mercado, como: os bancos, as seguradoras e as financeiras. O estudo não abrange o âmbito de estratégias de gestão de pessoas em relação à diversidade de gênero, e sim se baseia apenas na análise do 
comportamento do consumidor e seus impactos frente às suas percepções quanto às questões relacionadas ao gênero dos que ocupam posições de liderança.

\subsection{Relevância do estudo}

Este trabalho procura auxiliar as organizações no posicionamento e com estratégias de marketing, frente à percepção do consumidor sobre mulheres em posições de alto escalão. As empresas atualmente devem estar constantemente alinhando estratégias com objetivo de ganhar notoriedade para suas marcas por meio da compreensão do público e ao mesmo tempo favorecer causas tão importantes para a sociedade como a inclusão da mulher. Entendendo o comportamento e a percepção do consumidor, tem-se a base para fornecer aos clientes aquilo que eles realmente esperam.

Além disso, o estudo será de grande importância para as universidades, podendo ser utilizado por alunos e professores na intenção de fornecer informações relacionadas ao tema. 


\section{Referencial Teórico}

Neste capítulo são apresentados e discutidos aspectos conceituais e estudos relacionados ao tema que servirão de base teórica para fundamentação e elaboração da pesquisa.

\subsection{A mulher e o mercado de trabalho no Brasil}

No Brasil atualmente, as mulheres vem ocupando cada vez mais seu espaço no mercado de trabalho e ganhando destaque em diversos setores. No entanto, as funções exercidas, os cargos e os salários ainda são inferiores quando comparados com os dos homens. Além disso, o sexo feminino ainda é associado às ocupações atribuídas socialmente que derivam da cultura machista fundamentada na sociedade onde enxergam a mulher como "do lar".

Segundo a Pesquisa Nacional por Amostra de Domicílios Contínua do IBGE (2016), as mulheres possuem mais educação formal e ocupam $44 \%$ das vagas de emprego registradas no Brasil. Além disso, o numero de mulheres desempregadas é consideravelmente maior do que o de homens. Vale ressaltar que a diferença salarial ainda é vigente nos dias de hoje e segundo o Fórum econômico mundial (2018) o tempo estimado para que isso desapareça é de 100 anos. Atualmente os homens recebem aproximadamente $25,5 \%$ a mais que as mulheres.

Além das dificuldades enfrentadas no mercado de trabalho, a realidade da maioria das mulheres é ter que lidar com mais um desafio, a dupla jornada, termo definido pela Pesquisa Nacional por Amostra de Domicílios Contínua do IBGE (2016). A dupla jornada da mulher diz respeito à realização além do trabalho formal, sendo responsável também pelos afazeres domésticos e pelo cuidado de dependentes, como os filhos (IBGE, 2016).

Ainda de acordo com o estudo do Fórum Econômico (2018), uns dos principais motivos para que as mulheres não estejam tanto quanto os homens no mercado de trabalho foram à falta de opções de cuidados infantis e ter que lidar com as tarefas 
domésticas. Isso é uma realidade que as mulheres brasileiras enfrentam há séculos, a dupla jornada as mantém longe de empregos e principalmente longe de alcançarem funções de liderança.

De acordo com a ORGANIZAÇÃO INTERNACIONAL DO TRABALHO (2019), "a divisão das tarefas domésticas por gênero ainda é assustadoramente desigual. As mulheres se encarregam de $80 \%$ das tarefas do lar, o que restringe sua participação efetiva no mundo do trabalho". Com isso, a OIT também se pronunciou recomendando as empresas a adotarem políticas de inclusão do sexo feminino.

Portanto, segundo Silva et al.(2018),

apesar dos avanços, muitos obstáculos devem ser superados, dado que inúmeras mulheres precisam conciliar a dupla jornada (família e carreira), são responsáveis pela realização das atividades domésticas de mãe e esposa, sofrem discriminação social, cobranças de metas, incertezas profissionais, e adquirem doenças pelas condições estressantes que o trabalho propicia.

\subsubsection{Preconceito e estereótipos}

A partir da psicologia social, Crochík (1996) caracteriza o preconceito como algo individual, psicológico e que surge em função do processo de socialização e do desenvolvimento da cultura.

Gordon Allport (1954) elaborou um método em seu livro chamado "A natureza do preconceito" para determinar o grau de intolerância da sociedade, ou seja, o preconceito. O método ficou conhecido como Escala Allport, que possui níveis do 1 ao 5 os quais são:

- Nível 1- Antilocução: O grupo majoritário faz piadas sobre um grupo minoritário com termos negativos e estereótipos. Geralmente visto como inofensivo pela maioria.

- Nível 2- Esquiva: O contato com o grupo minoritário passa a ser evitado.

- Nível 3- Discriminação: O grupo minoritário é discriminado e negam oportunidades e serviços aos mesmos, prejudicando-o de atingir seus objetivos, obter educação, empregos etc. 
- Nível 4- Ataque físico: O grupo majoritário ataca tanto os pertences pessoais do grupo minoritário quanto os indivíduos fisicamente.

- Nível 5- Extermínio: O grupo majoritário buscar exterminar o grupo minoritário.

A Escala descrita será utilizada para fundamentação do presente estudo. Ainda de acordo com o psicólogo Allport (1954), o preconceito pode ser definido como uma atitude hostil contra um indivíduo, tão somente por ele pertencer a um grupo desvalorizado socialmente.

Quanto ao mercado de trabalho, pode-se afirmar que o preconceito é uma das causas básicas dos problemas que as mulheres enfrentam todos os dias (LAROUCHE E RYAN, 1991). A entrada das mulheres no mercado de trabalho aparentemente afetou pouco as organizações, devido ao sutil, mas poderoso preconceito que se encontra enraizado nos indivíduos e permanece como uma das hipóteses fundamentais que influenciam e dão forma à cultura da organização (LODEN, 1988). "O preconceito masculino, consciente ou inconsciente, continua a ser o grande obstáculo que a maioria das lideres femininas enfrentam nas organizações" (LODEN, 1988).

$\mathrm{Na}$ visão de Perreault (2008), a segregação nas relações de trabalho está diretamente relacionada a estereótipos e a segregação sexual dos empregos é clara, uma vez que as condições de trabalho variam, dependendo de quem ocupa o cargo, homens ou mulheres. Moscovici (1978) diz que as representações sociais dos gêneros configuram uma forma de exercer um estado de desequilíbrio o que favorece dessa forma, a perpetuidade de percepções quanto à inferioridade física e intelectual das mulheres em relação aos homens, além disso, favorece a subordinação e opressão.

\subsubsection{Sexismo}

Muito se fala em machismo e feminismo nos dias de hoje porem a questão do sexismo é pouco abordada e esclarecida. É de extrema importância que o termo seja esclarecido para assim analisar e avaliar o comportamento e postura dos indivíduos na sociedade. 
De acordo com Madureira (2007) o sexismo corresponde a uma separação exclusiva entre os gêneros masculino e feminino, ao estabelecimento de relações de poder desiguais e à associação de significados pejorativos em relação a um dos gêneros. Sexismo nada mais é que o preconceito em relação a um determinado gênero ou identidade sexual, e o seu conceito está totalmente entrelaçado com estereótipos e papeis de gênero impostos pela sociedade.

"A sociedade em que vivemos é sexista e naturaliza atos de preconceito de gênero. Muitos desses atos são realizados de forma passiva, sem que a pessoa perceba o teor sexista presente nessa ação" (AVELINO, 2019). O fato da cor azul ser associada aos homens e a cor rosa às mulheres é um exemplo claro do cotidiano de sexismo, o qua é atribuído ao indivíduo de forma natural desde a infância.

\subsection{A mulher no setor bancário}

Segundo o Ministério da Educação (2001), a importância dos bancos no setor financeiro é avaliada a partir das informações sobre o número de empregos e estabelecimentos (unidades locais) das empresas nas diversas atividades financeiras, sendo o setor bancário responsável por $69,9 \%$ do total de empregos do setor financeiro. Analisando o mercado em questão, temos como os principais players atualmente o ItaúUnibanco, Bradesco, Banco do Brasil, a Caixa Econômica Federal e o Santander (RELATORIO DE ESTABILIDADE FINANCEIRA DO BANCO CENTRAL DO BRASIL, 2018).

De acordo com os dados mais recentes da Relação Anual de Informações Sociais (RAIS, 2017), o setor bancário no Brasil possui 467.686 trabalhadores, sendo que 49,0\% são mulheres. Apesar de possuírem alta escolaridade, $83,8 \%$ das mulheres completaram o ensino superior porem às mesmas recebem remunerações inferiores à dos homens.

De acordo com um levantamento realizado pela subseção do Dieese na Confederação Nacional dos Trabalhadores do Ramo Financeiro (CONTRAF-CUT, 2019), a mulher bancária recebe em média 17,8\% menos que o homem em um cargo correspondente no Brasil. Ainda segundo a pesquisa, nos cinco maiores bancos do país, a ocupação do sexo feminino nos cargos de direção é pequena. Na direção da Caixa, elas são apenas 2,7\%. No Banco do Brasil, 4,84\%. No Bradesco, elas ocupam 5,15\% das posições de liderança. No Itaú, esse número é de $12,7 \%$. Já o Santander por sua vez 
alcança números um pouco mais elevados com 20,20\%. Para a presidente da ContrafCUT, Juvandia Moreira (2019), tais números apresentados revelam a discriminação de gênero no setor. "Esse é um dado verificado em toda a sociedade e em empresas de todos os segmentos econômicos. As mulheres recebem menos do que os homens, mesmo tendo a mesma função e cumprindo as mesmas tarefas". (MOREIRA, 2019)

Independente de possuir as mesmas formações que os correspondentes masculinos, ou até formações superiores, as mulheres ainda ficam com cargos e salários inferiores.

A partir da avaliação de politicas dos bancos brasileiros do Guia dos Bancos Responsáveis (GBR, 2018) realizado pela Idef e Contraf, organizações do GBR, foi feita uma análise em relação à igualdade de gênero e suas politicas. Foram atribuídas notas de 0 a 10 aos 9 maiores bancos do Brasil onde foi levado em consideração as políticas dos bancos sobre igualdade salarial, assédio e representatividade das mulheres nos cargos da alta administração. O quadro 1 revela as notas atribuídas em que se observa a média insatisfatória dos bancos, que foi de 1,4.

Além disso, a análise constatou que a porcentagem de mulheres nos altos cargos não chega a $30 \%$ em nenhum dos bancos avaliados, assim como pouco se fala em politicas que ajudem as mesmas a subirem de cargo. Apesar disso, todos possuem políticas de tolerância zero com qualquer tipo de discriminação de gênero e assédio.

Tabela 1- Notas dos bancos no tema Igualdade de gênero

\begin{tabular}{|l|c|}
\hline Banco & Nota \\
\hline BNDES & $\mathbf{2} \mathbf{4}$ \\
\hline $\begin{array}{l}\text { BB } \\
\text { Itaú } \\
\text { Santander }\end{array}$ & $\mathbf{1 , 8}$ \\
\hline Caixa & $\mathbf{1 , 2}$ \\
\hline $\begin{array}{l}\text { Bradesco } \\
\text { Votorantim }\end{array}$ & $\mathbf{1 , 1}$ \\
\hline $\begin{array}{l}\text { BTG Pactual } \\
\text { Safra }\end{array}$ & $\mathbf{0 , 7}$ \\
\hline
\end{tabular}

Fonte: Guia dos bancos responsáveis (2018). 
O Banco do Brasil vem adotando algumas eventuais iniciativas referentes a tentar mudar tal conjuntura. Dentre os pactos e acordos de responsabilidade socioambiental o mesmo adotou a meta corporativa de nomeação de mulheres em cargos de $1^{\underline{a}}$ Gestora de Unidades de Negócios. Além disso, ainda de acordo com o Guia dos bancos responsáveis (2018) o banco identificou oportunidades de aumentar a participação das mulheres nos cargos em que foram observados maior desigualdade de gênero, porem ainda não foram encontrados dados que revelem políticas oriundas de tais oportunidades destacadas.

\subsection{Liderança feminina}

O termo liderança diz respeito ao processo de coordenar o desempenho das pessoas, dando rumo ao alcance de alguns objetivos estabelecidos, sendo então a capacidade de dirigir e conduzir outras pessoas a buscar resultado a partir de seu comportamento (CHIAVENATO, 2004).

De fato, abordagens diferentes de liderança baseadas em gêneros, possuem diferenças gritantes. Por outro lado, como pontua Loden (1988), também possuem suas características em comum, visto que a autora afirma que todos os executivos possuem um único propósito: usar seu poder para influenciar os outros e alcançar objetivos.

Quanto à liderança feminina, Frankel (2007) argumenta que todas as mulheres são naturalmente líderes, e certas características exclusivas da mulher são o que fazem a grande diferença no conceito de liderança que as empresas buscam atualmente. A executiva brasileira nos dias de hoje se mostra significativamente indiferente ao poder, ela não quer mandar, como o homem; quer ter a capacidade de influenciar as pessoas, de ser reconhecida como sábia, sensata, capaz, quer ser um modelo (COHEN, 2009).

Rodrigues e Silva (2015) complementam:

A liderança feminina é vista como uma mudança de caráter cultural, pois se acredita que as mulheres possuam a mesma capacidade que os homens quando se trata de gestão, mesmo que ainda enfrentem limitações. Hoje, elas têm ocupado cargos que antigamente eram somente para homens, e isso ainda pode gerar conflitos e competitividade entre os gêneros, desvalorização e até mesmo pensamentos machistas. Ainda assim, desde que estejam bem 
preparadas, trazem um crescimento maior na forma de liderar e na distribuição de tarefas confiada a elas, que são mais fiéis, sinceras e delicadas quanto à execução de suas funções e proporcionam um ambiente de trabalho mais harmonioso.

De acordo com o estudo Woman in Business, realizado pela Grant Thornton (2019) com cerca de 4500 empresários em 35 países, as mulheres ocupam 25\% dos cargos de liderança dentro das empresas no Brasil. Globalmente, a média de presença feminina em cargos de liderança é de 29\%. Quando se trata do papel de CEO ou diretoria executiva, apenas $15 \%$ das empresas possuem uma mulher liderando o negócio.

"Ao longo dos anos, as mulheres vêm acumulando conquistas importantes no mercado de trabalho. Por outro lado, as desigualdades históricas de gênero em termos ocupacionais persistem, sobretudo se mencionarmos que as mulheres constituem minoria nas ocupações de maior status, como, por exemplo, cargos de alta gerência e posições executivas, como chief executive officer (CEO), chief financial officer (CFO), chief operations officer (COO), além dos boards de diretores" (HRYNIEWICZ e VIANNA, 2018).

A Calyper Estratégias Humanas do Brasil (2007), em parceira com a HSM Educação Executiva, realizou uma pesquisa com 66 mulheres que ocupavam cargos de presidência, vice-presidência e diretoria em empresas públicas e privadas. A pesquisa teve como foco traçar o perfil da executiva brasileira e disponibilizou a tabela abaixo com os dados que revelam a distribuição das participantes por setor de atividade econômica. Pode-se perceber que o segmento de serviços financeiros, foco de análise deste estudo, não possui grande representatividade. 
Tabela 2- Distribuição por setor de atividade econômica

\begin{tabular}{|c|c|c|}
\hline Setor & Quantidade & Percentual \\
\hline Acessórios e Cosméticos & 3 & $4,5 \%$ \\
\hline Automotiva & 1 & $1,5 \%$ \\
\hline Comidas e Bebidas & 11 & $16,7 \%$ \\
\hline Comunicação e Mídia & 7 & $10,6 \%$ \\
\hline Educação e Consultoria & 10 & $15,2 \%$ \\
\hline Energia - Elétrica e Petróleo & 2 & $3,0 \%$ \\
\hline Esportes & 1 & $1,5 \%$ \\
\hline Fabricação e Construção & 3 & $4,5 \%$ \\
\hline Impressão, Papéis e Pacotes & 2 & $3,0 \%$ \\
\hline Saúde - Produtos e Serviços & 7 & $10,6 \%$ \\
\hline Seguradoras & 1 & $1,5 \%$ \\
\hline Serviços Financeiros & 4 & $6,1 \%$ \\
\hline Serviços Governamentais & 1 & $1,5 \%$ \\
\hline Serviços em Tecnologia da Informação & 3 & $4,5 \%$ \\
\hline Telecomunicações & 7 & $10,6 \%$ \\
\hline Transportes & 1 & $1,5 \%$ \\
\hline Viagem, Hotéis e Lazer & 2 & $3,0 \%$ \\
\hline Total & 66 & $100 \%$ \\
\hline
\end{tabular}

Fonte: Caliper (2007).

\subsection{Percepção do consumidor}

Para compreender como os consumidores percebem as mulheres em posições de liderança, primeiro devemos entender o comportamento dos consumidores em geral. De acordo com Solomon (2012) "o comportamento do consumidor é o estudo dos processos envolvidos quando indivíduos ou grupos selecionam, compram, usam ou descartam um produto, serviços ideias ou experiências para satisfazerem necessidades e desejos". Kotler e Keller (2012) complementam dizendo que os indivíduos são influenciados por diversos fatores que constituem sua identidade, seu comportamento e seu estilo de vida. Estes fatores atuam diretamente no comportamento do consumidor e se dividem em quatro, sendo eles: culturais; sociais; pessoais e psicológicos.

Quanto à percepção Solomon (2016), define como o processo no qual as sensações humanas são selecionadas, organizadas e interpretadas. O autor argumenta ainda que quando uma empresa compreende o que os consumidores pensam a respeito de um conjunto de marcas, ela pode utilizar essas constatações para desenvolver uma estratégia de posicionamento, um componente fundamental das iniciativas de marketing de uma organização. No marketing, as percepções são mais importantes do que a realidade porque elas afetam o comportamento real do consumidor (Kotler e Keller, 2012). 
Kotler e Keller (2012) constataram que a percepção é um processo dinâmico pelo qual as pessoas conseguem interpretam as informações recebidas para criar uma imagem significativa do mundo. A percepção é individual e sofre influência de fatores físicos, de estímulos do ambiente e das condições internas individuais. Logo, o individuo como consumidor, sofre influências psicológicas, pessoais, sociais e culturais. Ainda de acordo om os autores, os clientes podem ter diferentes percepções de algo devido a três processos, sendo eles: atenção seletiva, distorção seletiva e retenção seletiva. A atenção seletiva consiste na capacidade dos consumidores em filtrar estímulos que possuem relação com alguma necessidade ou interesse. Já a distorção seletiva é a tendência dos consumidores em transformar uma informação em significados e experiências pessoais e assim interpretá-la segundo seus prejulgamentos. Por fim, a retenção Seletiva consiste na tendência dos consumidores em reter informações que confirmam suas crenças e atitudes.

\subsection{Posicionamento}

Para Kotler e Keller (2012) o posicionamento procura definir a marca no presente assim como mostrar o que ela poderia ser no futuro. Ries e Trout (2009) complementam dizendo que a essência do posicionamento consiste em aceitar as percepções como realidade e dessa forma reestruturá-las a fim de criar a percepção desejada. 0 posicionamento trata-se de uma decisão estratégica crucial para as organizações uma vez que como elas se posicionam é um ponto fundamental para a percepção dos clientes e suas decisões de escolha (HARRISON-WALKER, 2013).

A partir das teorias acima, tem-se fundamentos para analisar como diversas empresas do mercado bancário se posicionam e verificar se suas condutas correspondem com o que dizem. O Itaú Unibanco declara em seu relatório de sustentabilidade (2017) que possui diretrizes específicas que ressaltam a valorização da diversidade sexual, de gênero, de etnia e raça. No entanto, os dados revelam outra realidade, de acordo com o Guia Dos Bancos Responsáveis (2019), a discriminação de gênero é clara. Diante de 118 pessoas que ocupam cargos de diretoria no banco, apenas 15 são mulheres, sendo então 103 homens ocupando os postos de gestão e comando. Em outros bancos a situação não é muito diferente, no Banco Bradesco, o seu relatório de sustentabilidade afirma a adesão de políticas de promoção de diversidade de gênero, porem os indicadores já citados 
anteriormente (capitulo 2.2) revelam que na diretoria, as mulheres são minoria. Uma vez que o posicionamento é crucial para a sobrevivência das marcas no mercado, os fatos descritos acima podem acarretar em graves consequências para as organizações se não buscarem rapidamente alinhar suas práticas a como se posicionam de fato no mercado. Certos consumidores podem demonstrar insatisfação ao perceberem as incoerências e não se sentirem representados. 


\section{Metodologia}

Este capítulo possui como principal objetivo informar sobre as diversas decisões acerca da forma como a pesquisa deste estudo foi realizada. Nesta seção informa-se o tipo de pesquisa, o universo e a amostra, os procedimentos e instrumentos de coleta de dados utilizados, as formas como os dados coletados foram tratados e analisados e, por ultimo, as limitações do método.

\subsection{Tipo de pesquisa}

Segundo Vergara (2000, p 44), existem várias taxonomias de tipos de pesquisa, assim, a autora propõe dois critérios básicos: quanto aos fins que uma pesquisa pode ter e quanto aos meios de investigação que ela pode adotar.

Quanto os fins, uma vez que o objetivo é entender e analisar a percepção dos consumidores, a pesquisa foi do tipo descritiva que, de acordo com Vergara (2000, p 45), "expõe caraterísticas de determinada população ou de determinado fenômeno. Pode também estabelecer correlações entre variáveis e definir sua natureza e não tem compromisso de explicar os fenômenos que descreve, embora sirva como base para tal explicação".

Quanto os meios de investigação, a pesquisa foi realizada por meio de coleta de dados em campo, fazendo uso de dois questionários. Tal meio de investigação, ainda de acordo com Vergara (2000), constitui uma investigação empírica e pode incluir entrevistas e aplicação de questionários.

\subsection{Universo e amostra}

A população da pesquisa é composta por homens e mulheres, das mais variadas idades, consumidores do mercado bancário no Brasil. 
Já a amostra utilizada foi não-probabilística, composta por 274 pessoas, sendo que 136 responderam o questionário 1 e 138 pessoas responderam o questionário 2, esses questionários serão detalhados adiante. A amostra foi selecionada por acessibilidade, em que, segundo Vergara (2000, p. 49), os elementos são selecionados pela facilidade de acesso do pesquisador a eles.

\subsection{Procedimentos e Instrumentos de Coleta de Dados}

O presente estudo utilizou-se da estratégia de levantamento e coleta de dados por meio de dois questionários contendo questões de múltipla escolha. Os mesmos foram distribuídos online por meio de redes sociais para os respondentes através da plataforma Qualtrics, que se trata de uma plataforma de survey on-line.

O primeiro questionário (Anexo 1) apresentava uma reportagem fictícia de um banco o qual possuía uma mulher como diretora. O segundo questionário (Anexo 2) apresentava a mesma reportagem, porém com um homem ocupando o cargo. Para facilitar a análise e comparação dos dados posteriormente, será usado como referência "questionário 1" e "questionário 2" para os questionários com a versão feminina e com a versão masculina respectivamente.

Os componentes da amostra foram divididos em dois grupos, de forma que cada um respondesse apenas a um dos modelos de questionário. Dessa forma, foi possível comparar as respostas entre os que receberam o questionário 1 e os que receberam o questionário 2. As primeiras questões dos questionários foram utilizadas para identificação do perfil dos respondentes, como: faixa etária, sexo, renda familiar, grau de escolaridade e de quais bancos era cliente. A segunda parte consistia em perguntas objetivas e afirmações curtas referentes à reportagem apresentada. As questões foram baseadas em indicadores que permitiram avaliar o nível de concordância dos respondentes em escalas adaptadas de Likert.

Foram aplicados 274 questionários. Dentre estes, 60 foram descartados por apresentarem inconsistências em algumas questões. Assim, a amostra final válida foi restringida a 214, sendo 99 do questionário 1 e 115 do questionário 2. 


\subsection{Tratamento dos dados}

Segundo Gil (1991), as pesquisas de levantamento, o que é o caso deste estudo, caracterizam-se pela interrogação direta das pessoas cujo comportamento se deseja conhecer. Basicamente, procede-se à solicitação de informações a um grupo considerável de pessoas sobre o problema estudado para, em seguida, mediante análise quantitativa, obter as conclusões dos respectivos dados coletados. Logo, o presente trabalho irá utilizar a abordagem quantitativa.

A análise dos dados foi baseada na estatística descritiva, por meio de medidas de tendência central, de variabilidade e dispersão.

Além disso, como citado anteriormente, a Escala de Allport foi utilizada como base para avaliar o nível de discriminação nos resultados encontrados.

\subsection{Limitações do método}

Existem certas limitações que deve ser consideradas no método utilizado, logo seus resultados não devem ser generalizados.

É importante ressaltar que a pesquisa não engloba toda a população de consumidores bancários do Brasil, pois a amostra é relativamente pequena e, assim, os resultados não representam todos os integrantes da população estudada.

Outra limitação se dá em relação à possibilidade de um respondente possuir uma ideia pré-concebida sobre o mercado estudado, o que influenciaria nas respostas dadas.

Por ultimo, os respondentes podem não ter compreendido algumas questões e marcado respostas sem veracidade ou comprometimento com a pesquisa, o que é inerente ao método. 


\section{Análise dos resultados}

Este capítulo possui o objetivo de apresentar e analisar os resultados obtidos por meio da pesquisa quantitativa e relacionar com as teorias abordadas. A análise está organizada em duas seções. A primeira diz respeito ao perfil dos respondentes e a segunda está relacionada com os resultados das questões e a análise da percepção dos entrevistados.

\subsection{Descrição e análise do perfil dos respondentes}

Como citado anteriormente, o questionário foi dividido em dois blocos. O primeiro tinha como objetivo investigar o perfil da amostra através de cinco perguntas objetivas. Do total de 214 respondentes, os dados revelaram que a maioria dos respondentes possuem entre 18 e 24 anos, o que corresponde a aproximadamente 56\% dos respondentes do questionário com a versão da diretora e 44\% do questionário com a versão do diretor, como pode ser observado nos gráficos 1 e 2.

Quanto ao gênero, observa-se no geral uma predominância do sexo feminino, com $69 \%$, e $31 \%$ do gênero masculino. De acordo com os gráficos 3 e 4, percebe-se, que a distribuição de ambos os questionários foi similar, sendo que o total de respondentes do sexo feminino no questionário 1 foi de $63 \%$ e no questionário 2 foi de $74 \%$.

Em relação ao nível de escolaridade, o grupo concentrou-se em respondentes com o ensino superior incompleto e completo. Em uma análise mais detalhada, 91\% e 84\% dos respondentes estão entre o ensino superior incompleto e a pós-graduação completa. Sobre a média de renda familiar, o critério foi selecionado de acordo com o IBGE, visto que 42,5\% selecionaram a opção "acima de 20 salários mínimos ( $\mathrm{R} \$ 15.760,01$ ou mais)". Já $21,5 \%$ estão entre 10 a 20 salários mínimos (De $R \$ 7.880,01$ a $R \$ 15.760,00$ ) e 17,3\% dos respondentes entre 4 a 10 salários mínimos (De $R \$ 3.152,01$ a $R \$ 7.880,00$ ). 
Gráfico 1- Resultado referente a "Q1: Qual a sua faixa etária?" - Questionário 1

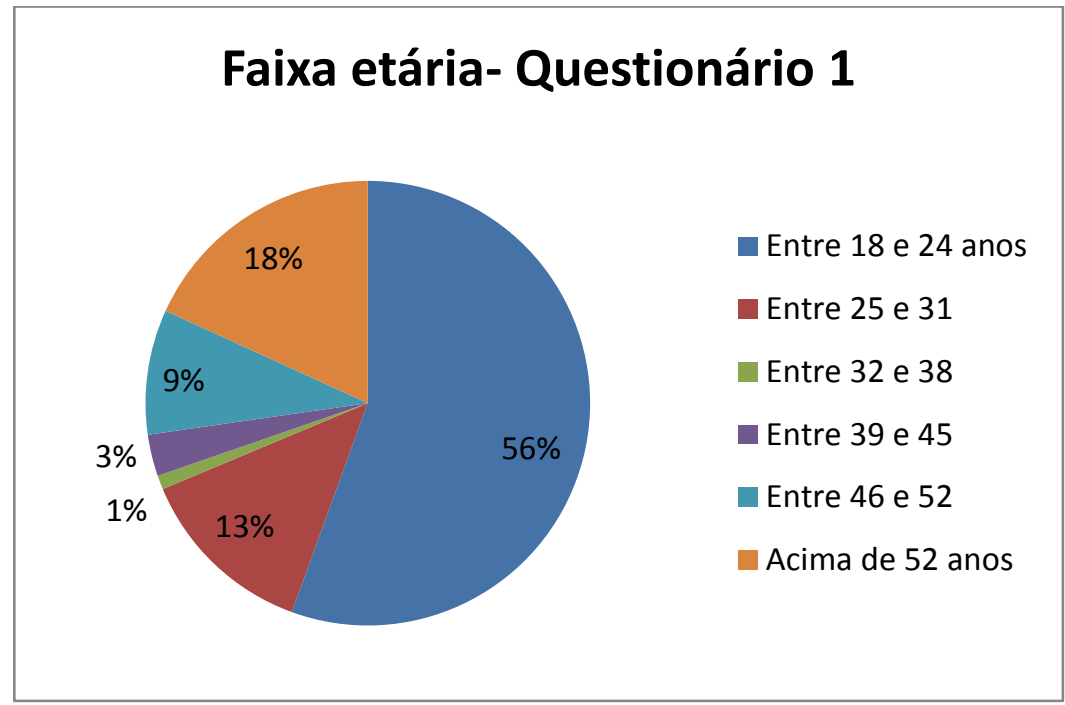

Fonte: própria (2019).

Gráfico 2- Resultado referente a "Q1: Qual a sua faixa etária?" - Questionário 2

\section{Faixa etária- Questionário 2}

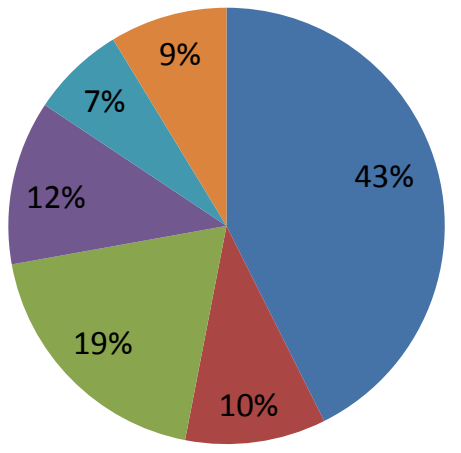

Entre 18 e 24 anos

- Entre 25 e 31

Entre 32 e 38

- Entre 39 e 45

Entre 46 e 52

Acima de 52 anos

Fonte: própria (2019). 
Gráfico 3- Resultado referente a "Q2: Qual o seu gênero?" - Questionário 1

\section{Gênero- Questionário 1}

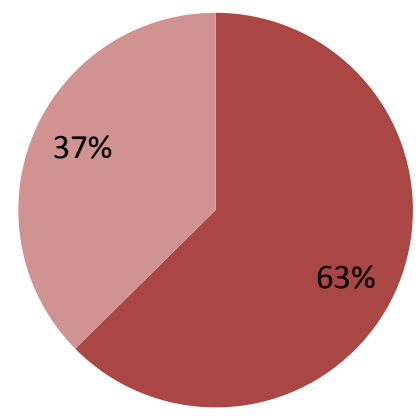

Feminino

Masculino

Fonte: própria (2019).

Gráfico 4- Resultado referente a "Q2: Qual o seu gênero?" - Questionário 2

\section{Gênero- Questionário 2}

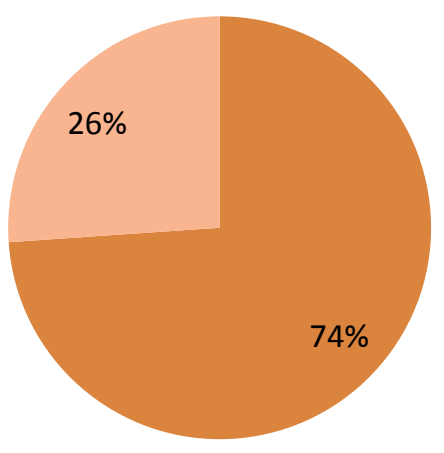

Feminino

Masculino

Fonte: própria (2019).

Na ultima pergunta do primeiro bloco, os respondentes deveriam selecionar dentre as diversas opções, de qual(is) banco(s) eram consumidores. De acordo com os dados da tabela 3, Itaú Unibanco, Banco do Brasil e Bradesco são os bancos que revelaram possuir maior parcela dos consumidores em que, respectivamente, 41,4\%, 31,6\% e 23,7\% são os bancos com mais clientes pesquisados. 
Tabela 3 - Resultado referente a "Q5: De qual(is) banco(s) abaixo você é consumidor?" Questionários 1 e 2

\begin{tabular}{lccc}
\hline $\begin{array}{c}\text { De quais bancos você é } \\
\text { consumidor? }\end{array}$ & $\begin{array}{c}\text { \% } \\
\text { Respondentes do } \\
\text { Questionário 1 }\end{array}$ & $\begin{array}{c}\text { \%espondentes do } \\
\text { Questionário 2 }\end{array}$ & $\begin{array}{c}\% \\
\text { De todos os } \\
\text { respondentes }\end{array}$ \\
\hline Banco do Brasil & $16,6 \%$ & $18,4 \%$ & $31,6 \%$ \\
\hline Caixa Econômica & $5,0 \%$ & $18,4 \%$ & $21,9 \%$ \\
\hline Itaú Unibanco & $30,4 \%$ & $16,4 \%$ & $41,4 \%$ \\
\hline Bradesco & $12,2 \%$ & $14,0 \%$ & $23,7 \%$ \\
\hline Santander & $8,8 \%$ & $10,6 \%$ & $17,7 \%$ \\
\hline BTG Pactual & $1,1 \%$ & $1,0 \%$ & $1,9 \%$ \\
\hline Safra & $1,7 \%$ & $1,0 \%$ & $2,3 \%$ \\
\hline Banco Inter & $3,9 \%$ & $2,9 \%$ & $6,0 \%$ \\
\hline Nubank & $13,8 \%$ & $12,1 \%$ & $23,3 \%$ \\
\hline Outro & $6,6 \%$ & $5,3 \%$ & $10,7 \%$ \\
\hline
\end{tabular}

Fonte: Própria (2019).

\subsection{Análise da percepção dos consumidores}

No segundo bloco do questionário, o respondente, após ler a reportagem, foi questionado, de acordo com sua opinião, qual seria a responsabilidade do profissional citado no texto pelos resultados obtidos pela organização. Em uma escala de 1 (significando "nenhuma") a 10 (significando "muita") deveria ser escolhida a alternativa. A partir do cálculo da média das respostas encontradas na tabela 4, foi possível comparar os questionários. 
Tabela 4- Resultado referente a "Q7: Qual é a responsabilidade do profissional pelos resultados da organização?" - Questionários 1 e 2

\begin{tabular}{lcc}
\hline \multicolumn{3}{c}{ Grau de Responsabilidade } \\
\hline Escala de 1 a 10 & \% Questionário 1 & \% Questionário 2 \\
\cline { 2 - 3 } Grau 1 & $1,0 \%$ & $1,7 \%$ \\
\hline Grau 2 & $1,0 \%$ & $0,0 \%$ \\
\hline Grau 3 & $7,1 \%$ & $1,7 \%$ \\
Grau 4 & $4,0 \%$ & $7,8 \%$ \\
\hline Grau 5 & $13,1 \%$ & $5,2 \%$ \\
\hline Grau 6 & $15,2 \%$ & $13,0 \%$ \\
\hline Grau 7 & $16,2 \%$ & $18,3 \%$ \\
Grau 8 & $20,2 \%$ & $21,7 \%$ \\
Grau 9 & $9,1 \%$ & $13,9 \%$ \\
Grau 10 & $13,1 \%$ & $16,5 \%$ \\
\hline
\end{tabular}

Fonte: Própria (2019).

Quadro 1- Média referente aos resultados da questão 7- Questionário 1

$\begin{array}{cccc}\text { \# Campo } & \text { Mínimo } & \text { Máximo } & \begin{array}{c}\text { Média } \\ \text { padrão }\end{array} \\ & \text { 7. Na sua opinião, qual é a responsabilidade dessa profissional pelos } \\ \text { resultados da organização? Em uma escala de 1 (significando } & 1.00 & 10.00 & 6.87 \\ \text { "nenhuma") a } 10 \text { (significando "muita"), escolha a alternativa. }\end{array}$

Fonte: Qualtrics Survey Software (2019).

Quadro 2- - Média referente aos resultados da questão 7 - Questionário 2

$\begin{array}{cccc}\text { \# Field } & \text { Mínimo } & \text { Máximo } & \begin{array}{c}\text { Média } \\ \text { padrão }\end{array} \\ 1 \text { 7. Na sua opinião, qual é a responsabilidade desse profissional pelos } \\ \text { resultados da organização? Em uma escala de 1 (significando } \\ \text { "nenhuma") a } 10 \text { (significando "muita"), escolha a alternativa. }\end{array}$

Fonte: Qualtrics Survey Software (2019). 
Como pode se observar, na tabela 4 e nos quadros 1 e 2, o questionário com a versão do diretor obteve uma média maior, sendo de 7,34. Já a média encontrada no questionário com a versão da diretora foi de 6,87. Mesmo que sutil, a diferença existe, 0 atributo "responsabilidade" foi associado mais aos homens do que às mulheres. Dessa forma, os respondentes alegaram acreditar que o diretor possui maior responsabilidade sobre os resultados da organização, demonstrando uma diferença devida tão somente ao gênero do ocupante do cargo.

Mais adiante na pesquisa, foram expostas seis palavras, e o respondente deveria completar a frase marcando o atributo que mais se adequava de acordo com sua opinião, ou selecionar a opção de manter-se neutro. Na seguinte frase do questionário 1: "Por ser mulher, a diretora provavelmente possui uma postura mais.." os entrevistados em sua maioria não possuíam opinião formada. Já em segundo e terceiro lugar, de acordo com a tabela 5, as escolhas foram: sábia e coerente. As respostas da frase no questionário 2, com a versão masculina, em sua maioria também foram "não possuo uma opinião formada", porém em segundo lugar se identificaram mais com o atributo "racional".

Os dados assim comprovam que os estereótipos ainda estão enraizados na sociedade, os quais acabam por determinar o lugar da mulher no mercado de trabalho, em particular no setor bancário. A partir da pesquisa, a diretora foi associada como sábia e coerente e o diretor como racional, percepções estas que segundo Araujo (2003, p.1) são oriundas desde os primórdios, em que a mulher é "moldada para executar tarefas mais manuais, ser mais delicada, comunicativa, sociável e submissa ao homem, que ao contrário é considerado forte, arrojado e está mais preparado para tarefas de comando, decisão, cálculos." 
Tabela 5- Resultado referente a "Q10: Postura dos diretores" Questionários 1 e 2

\begin{tabular}{lcc}
\hline Atributos & \% Questionário 1 & \% Questionário 2 \\
\cline { 2 - 3 } Sábio (a) & $14,1 \%$ & $3,0 \%$ \\
Racional & $12,1 \%$ & $26,7 \%$ \\
Coerente & $16,1 \%$ & $8,1 \%$ \\
\hline Frágil & $1,0 \%$ & $2,6 \%$ \\
Incoerente & $1,0 \%$ & $1,0 \%$ \\
\hline Emotivo (a) & $3,0 \%$ & $1,7 \%$ \\
\hline Não possuo opinião formada & $52,5 \%$ & $56,9 \%$ \\
\hline Fonte: Própria (2019) & & \\
\hline
\end{tabular}

Fonte: Própria (2019).

Nas próximas perguntas do questionário que serão abordadas, foi utilizada a escala de Likert a fim de analisar o nível de concordância dos entrevistados com uma afirmação.

A afirmação "A diretora sabe avaliar as consequências de suas decisões estratégicas" apresentou maior concordância parcial pelos respondentes do questionário 1. A maioria, de acordo com o gráfico 5 , demonstrou não possuir opinião formada, e $35,35 \%$ não concordaram nem discordaram. Já ao analisar o gráfico 6 , grande parte dos respondentes $(42,37 \%)$ concordou parcialmente com a afirmação na versão do diretor, $13 \%$ a mais que a versão da diretora, e menos pessoas demonstraram-se neutras. Podese inferir, neste sentido, que quando se trata de um homem, os consumidores o percebem como mais capaz de analisar suas decisões estratégicas, ou, em outras palavras, acreditam que ele sabe mais do que está fazendo. Este é o grande " $X$ da questão", pois os resultados demonstram, em tese, que uma mulher não possui o mesmo discernimento que um homem, como se o fato da diretora ser mulher a desacreditasse e desabonasse como líder e funcionária.

Outra inferência que pode ser feita é que, as pessoas se mostraram mais neutras na afirmação do questionário 1 por talvez não possuírem coragem de afirmar que a diretora não saberia avaliar suas consequências, ou por simplesmente não querer ter que refletir sobre o assunto, ignorar e manter-se neutro foi uma opção mais fácil e que exigiu 
menos esforço. Já no questionário 2, houve mais certeza e menos imparcialidade; os respondentes; em sua maioria; possuíram uma opinião mais formada automaticamente por se tratar do sexo masculino na questão. Pode-se dizer, desta forma, que apesar de alguns indivíduos se posicionarem como indiferentes ou até mesmo contra a discriminação de gênero, as pessoas sem ao menos perceberem, acabam por preferir o sexo masculino em determinadas ocasiões, fato este possivelmente decorrente da cultura sexista imposta pela sociedade e adotada pelas organizações.

Gráfico 5- Resultado referente a "Q9:A diretora sabe avaliar as consequências de suas decisões estratégicas" - Questionário 1

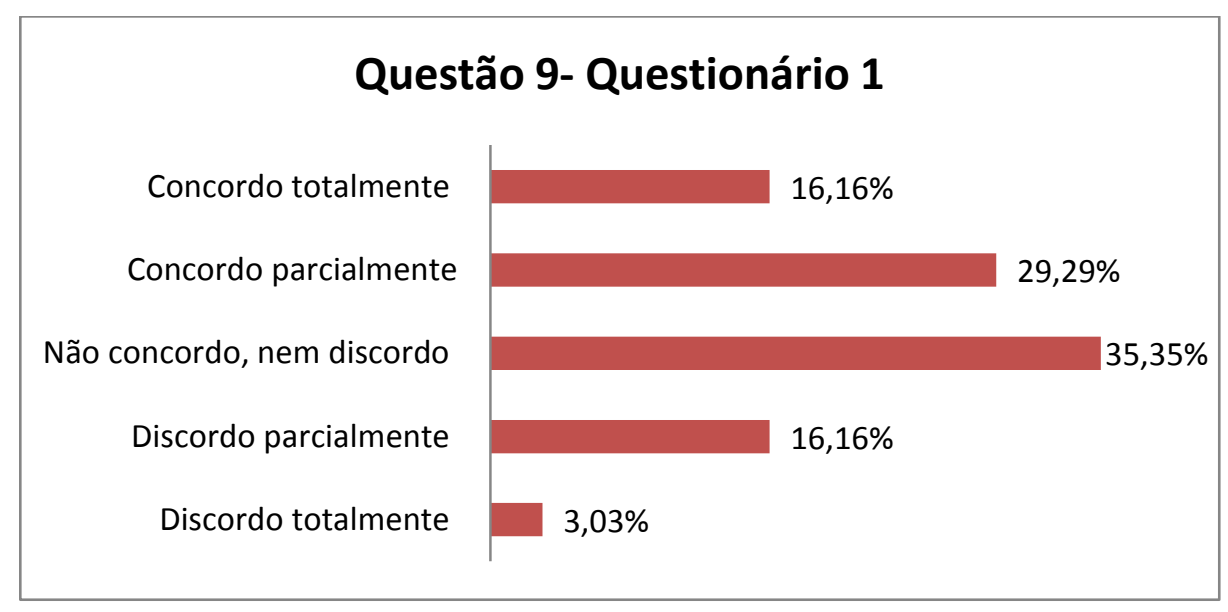

Fonte: Própria (2019).

Gráfico 6- Resultado referente a "Q9: O diretor sabe avaliar as consequências de suas decisões estratégicas"- Questionário 2

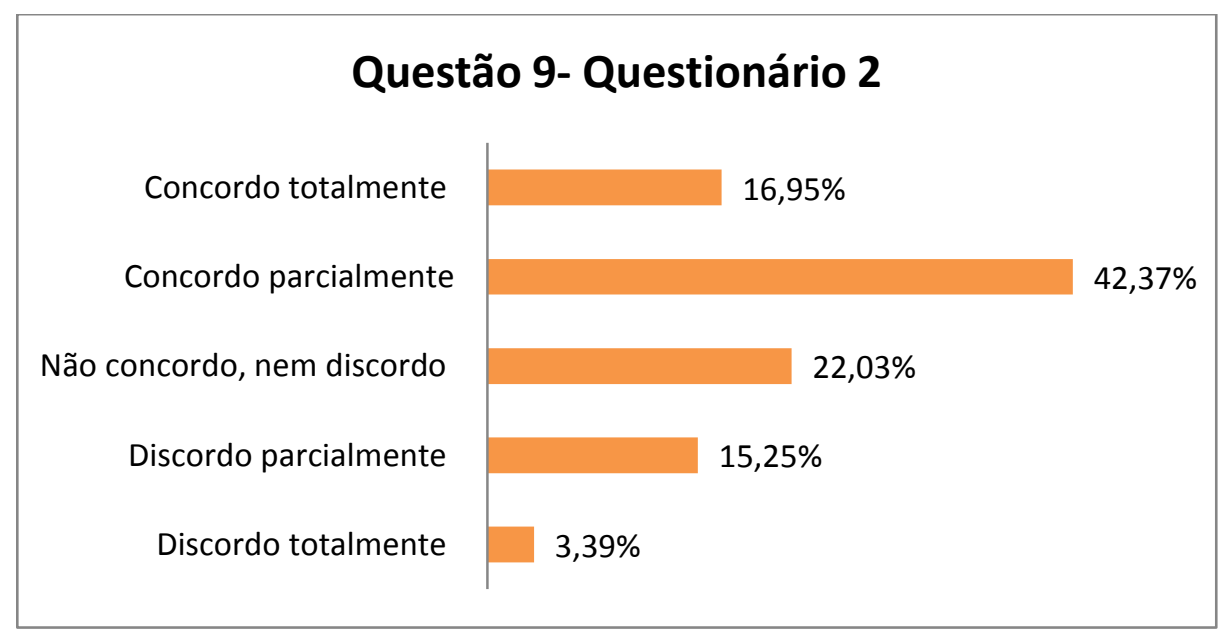


Fonte: Própria (2019).

A pesquisa também buscou analisar o ponto de vista dos pesquisados quanto às dificuldades diárias enfrentadas pelas mulheres no ambiente de trabalho, especificamente nos bancos. Conforme consta no gráfico 7, 64,3\% dos respondentes concordaram de parcialmente a totalmente que a mulher encontra dificuldades específicas no dia a dia, devido ao gênero. O gráfico 8 revela que a grande maioria $(70 \%)$ discordou de que 0 homem encontra dificuldades especificas no dia a dia. Diante dos resultados, é valido afirmar que as pessoas possuem uma consciência sobre as diferenças existentes no dia a dia entre ambos os sexos e, não somente isso, mas também reconhecem que as mulheres enfrentam dificuldades em sua rotina, sejam essas variando desde pequenas discriminações até assédios, por parte de colegas de trabalho ou mesmo clientes. Apesar disso, uma parcela ainda significativa discordou da afirmativa no questionário 1 , fato este um pouco preocupante nos dias de hoje, em que a inclusão de gênero é um tema bastante pautado. É válido ressaltar a importância dos bancos se posicionarem frente à inclusão da mulher, para não somente reforçar a conscientização dos consumidores mas também poderem representar grande parte dos seus clientes, gerando confiança e valor aos mesmos.

Gráfico 7- Resultado referente a "Q11: No dia a dia dessa profissional, ela encontra dificuldades"Questionário 1

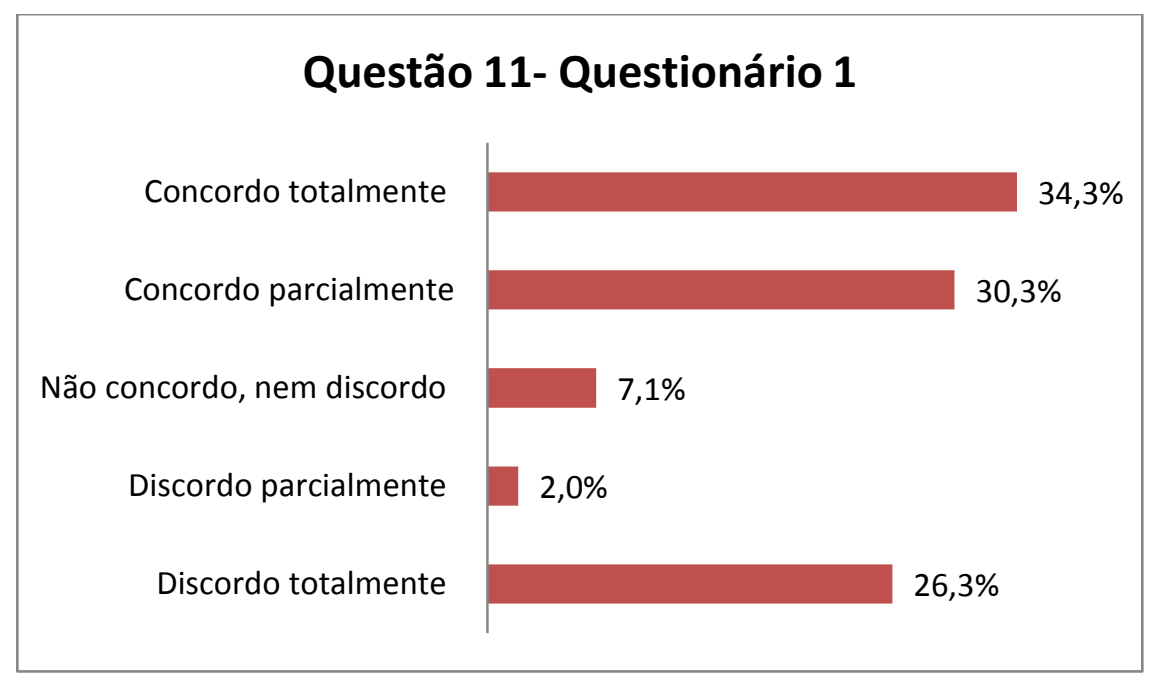

Fonte: Própria (2019). 
Gráfico 8- Resultado referente a "Q11: No dia a dia desse profissional, ele encontra dificuldades"Questionário 2

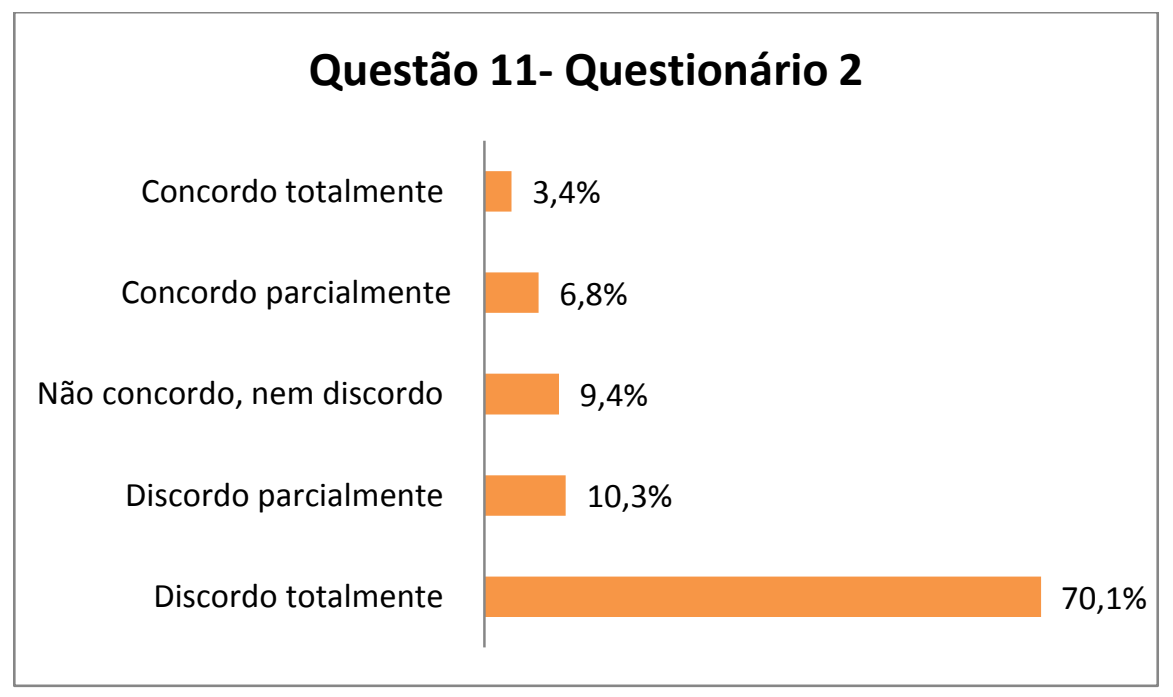

Fonte: Própria (2019).

Os sujeitos pesquisados, na penúltima questão do questionário, revelaram se entendem que o sexo do indivíduo influencia nas ações a serem tomadas e na postura do profissional. A maioria dos respondentes discordou totalmente da afirmativa, sendo que 0 percentual de respostas do questionário com a versão da diretora foi de $57,58 \%$ e do questionário 2, com a versão do diretor, foi de 40,17\%. Este dado de certa forma pode ser considerado um ponto positivo, uma vez que, partindo desse ponto de vista, os respondentes enxergaram o homem e a mulher como semelhantes, no entanto em todas as categorias houve pequenas diferenças nas respostas do questionário 2, de forma que os respondentes possuíram uma tendência em concordar com o fato de que ser homem influencia nas ações e postura do profissional. Quanto a isso não se pode concluir algo definitivo, pois não foi questionado de que maneira isso influencia, logo não pode ser avaliado como algo positivo ou negativo.

Por fim, na última questão da pesquisa, afirmou-se que se o sexo oposto ao do profissional da reportagem estivesse ocupando o mesmo cargo, o resultado alcançado pelo banco seria melhor. Conforme o gráfico 10, supreendentemente, $21,4 \%$ dos respondentes concordaram (parcialmente a totalmente) com a afirmativa do questionário 2, e $41 \%$ mantiveram-se neutros. É interessante que, tratando-se de perguntas menos 
diretas como as demais, a tendência foi valorizar e priorizar o homem, mesmo a maioria dos respondentes sendo mulheres. No entanto, quando confrontados diretamente com uma afirmação possuindo um teor discriminativo, os respondentes valorizaram e priorizaram a mulher. Isso demonstra que a sociedade está a par da situação enfrentada hoje pelas mulheres no Brasil e reconhecem a existência da discriminação de gênero. Contudo, a maioria, não se posiciona frente à causa e aparentemente não luta para desestruturar e desnaturalizar a cultura machista, que vem de maneira cada vez mais singela se perpetuando pelas gerações e contribuindo para dificultar a ascensão das mulheres aos cargos superiores.

Gráfico 9- Resultado referente a "Q13: Sendo um homem ao ocupar o mesmo cargo, o resultado seria melhor- Questionário 1

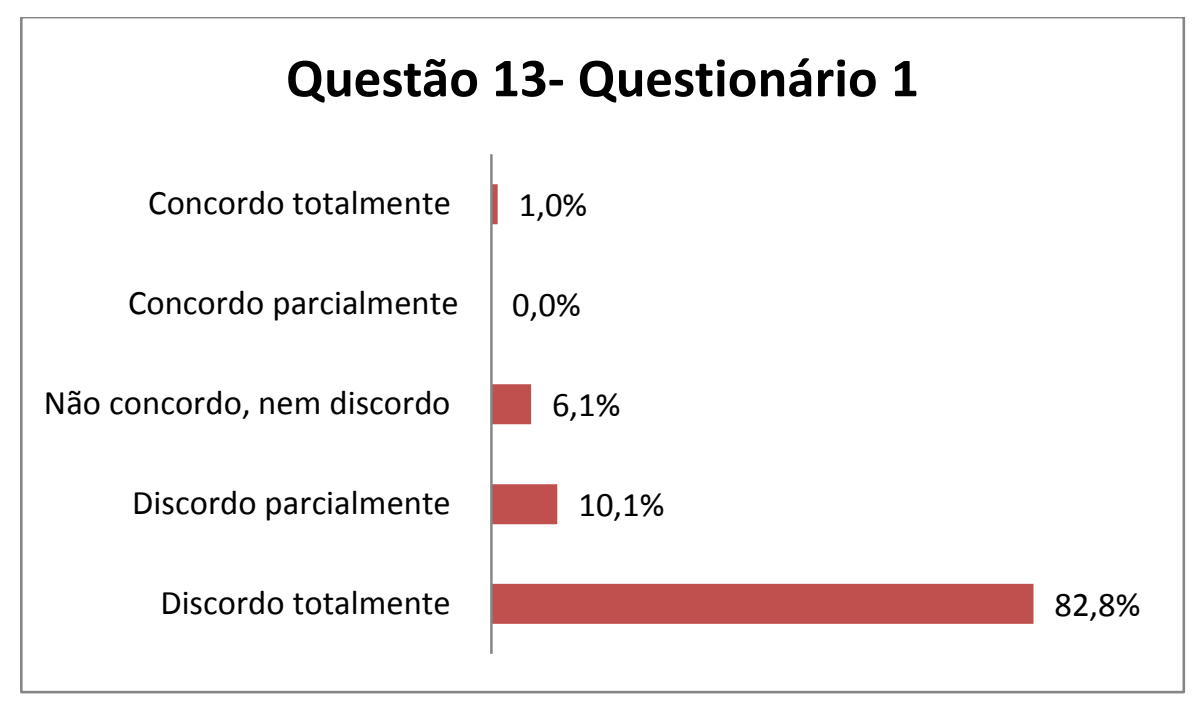

Fonte: Própria (2019). 
Gráfico 10- Resultado referente a "Q13: Sendo uma mulher ao ocupar o mesmo cargo, o resultado seria melhor"- Questionário 2

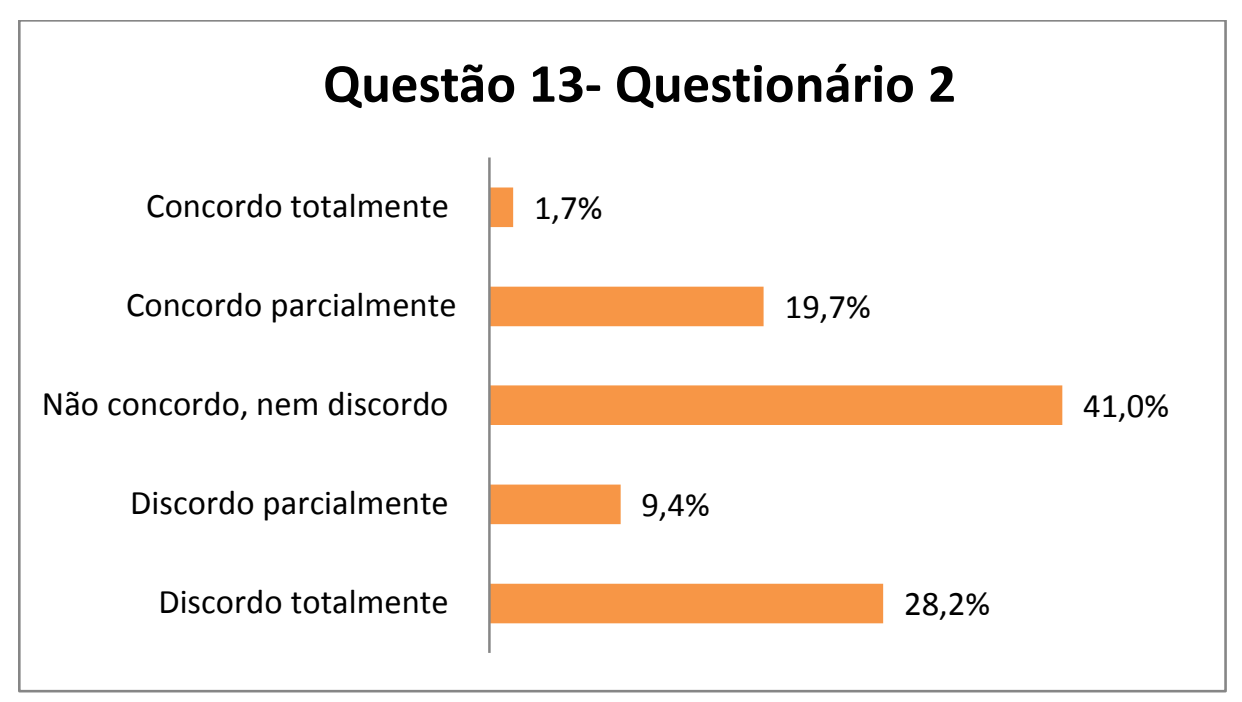

Fonte: Própria (2019).

Enxergando os resultados de maneira geral, a Escala de Allport, já relatada anteriormente, foi utilizada como base para avaliar o nível de preconceito das pessoas. Sob essa ótica, foi possível medir a intolerância dos consumidores bancários com as mulheres em cargos de liderança. De acordo com os dados encontrados na pesquisa, as mulheres nos bancos são vistas como inferiores e, complementar a isso, como foi abordado no referencial teórico, as mesmas não possuem oportunidades e condições iguais às dos homens. A realidade enfrentada pelo sexo feminino atualmente as dificulta no sentido de atingirem seus objetivos e interesses, logo se pode afirmar que a sociedade encontra-se no nível três da escala determinada por Gordon Allport (1954), em que a intolerância passa a ser caracterizada como discriminação. 


\section{Conclusão}

O presente trabalho pretendeu investigar à percepção dos consumidores frente a mulheres em cargos de liderança, focando no mercado bancário brasileiro. Essa questão se mostra relevante, uma vez que as novas tecnologias e mudanças organizacionais em um dos setores mais dinâmicos do país acarretaram um aumento da participação feminina no segmento e nos cargo de gerência. No entanto, os cargos de decisão, comando e direção permanecem concentrados na figura masculina (SANTOS, 2008). Além disso, mesmo quando inserida no mercado profissional, a mulher permanece acumulando papéis com a dupla jornada e recebendo salários e oportunidades inferiores. Logo, as lutas por reconhecimento e respeito devem ser constantes. Em uma sociedade que vem buscando cada vez mais a inclusão e por se tratar de um setor cada vez mais competitivo, a partir da compreensão da percepção dos consumidores, os bancos devem se posicionar imediatamente adotando estratégias frente à discriminação de gênero.

Sob essa ótica, o presente trabalho teve como objetivo analisar a percepção dos consumidores do mercado bancário sobre mulheres em cargos de liderança e, dessa forma, identificar possíveis oportunidades e ameaças.

Para aprofundar a análise pretendida, estudou-se sobre a inserção da mulher no mercado de trabalho no Brasil, as dificuldades enfrentadas no mercado bancário e a questão da liderança feminina. A fim de esclarecer diversos conceitos, também foram discutidos autores que abordam temas relacionados a estereótipos e discriminação de gênero. Por fim, buscou-se entender sobre o comportamento do consumidor a partir do estudo de diferentes perspectivas de autores, abordando teorias de marketing, percepção do consumidor e posicionamento.

Os objetivos do trabalho foram alcançados por meio de uma pesquisa descritiva, sendo realizados dois questionários para analisar a percepção do consumidor. Os componentes da amostra foram divididos em dois grupos, de forma que cada um respondesse apenas a um dos modelos de questionário. $O$ primeiro questionário apresentava uma reportagem fictícia de um banco o qual possuía uma mulher como 
diretora e contou com 99 respondentes. O segundo questionário foi respondido por 116 pessoas e possuía a mesma reportagem, porém com um homem na direção. A escolha da amostra foi baseada na acessibilidade e o tratamento dos dados foi feito por uma abordagem quantitativa, por intermédio de uma análise descritiva.

Observando a percepção das pessoas em relação às mulheres bancárias em posições superiores, foi possível notar que a grande maioria dos respondentes, apesar de reconhecerem as dificuldades e discriminações enfrentadas pelas mulheres no Brasil, ainda possuem em sua percepção estereótipos enraizados de maneira sutil, uma vez que no geral acabaram por preferir o sexo masculino em determinadas ocasiões. Logo, foi possível concluir que a maioria não se posiciona frente à causa e acaba por se acomodar com a realidade, mesmo que não estejam satisfeitos por completo. Diante disso, as organizações devem acompanhar as mudanças culturais e sociais, abraçando a inclusão de gênero de modo que altere a percepção do consumidor de forma positiva.

De maneira complementar, observou-se que os sujeitos pesquisados, de certa forma, percebem o sexo masculino como mais capaz de analisar suas decisões estratégicas enquanto liderança. A palavra "racional" foi associada ao homem e as palavras "sábia" e "coerente" á mulher, percepções estas oriundas de imposições sociais atribuídas desde os primórdios devido à cultura sexista que predomina no Brasil.

Por meio da Escala Allport, foi possível determinar o nível de preconceito dos consumidores bancários com as mulheres em cargos superiores. Uma vez que as mulheres nos bancos são vistas como inferiores e não possuem as mesmas oportunidades que os homens, o que as prejudica para atingir seus objetivos, a sociedade encontra-se no nível três, em que a intolerância passa a ser caracterizada como discriminação.

Portanto, o presente estudo aponta que a distinção de gênero nos cargos de liderança é de fato percebida pelo consumidor e cada vez mais isso deve ser utilizado para promover a inclusão da mulher, e não para a fomentação da discriminação de gênero. Isso de fato irá possibilitar uma aproximação dos consumidores, assim como a conscientização da sociedade, o que tende a acarretar uma vantagem competitiva frente à concorrência naqueles que vierem a se posicionar de tal forma. 


\section{Referências Bibliográficas}

AFP. Desvantagens de mulheres no mercado de trabalho vão além do salário. Exame Online, 27 ago. 2019. Disponível em: <https://exame.abril.com.br/carreira/desvantagensde-mulheres-no-mercado-de-trabalho-vao-alem-do-salario/>. Acesso em: 12 ago. 2019.

ALLPORT, G. W. The nature of prejudice. Wokingham: Addison-Wesley. 1954.

AVELINO, Lara. Sexismo: o que é, como reconhecer e combater esse preconceito. Dicas de mulher, 2019. Disponível em: <https://www.dicasdemulher.com.br/sexismo/>. Acesso em: 20 out. 2019.

ARAÚJO, H. A mulher no setor bancário. XXII SIMPÓSIO NACIONAL DE HISTÓRIA. Universidade Federal da Paraíba- João Pessoa, PB, 2003.

ARAÚJO, D; As palavras e seus efeitos: o sexismo na publicidade. Dissertação de Mestrado. Porto Alegre, PUCRS, 2006.

BANCO CENTRAL DO BRASIL. Relatório de Estabilidade Financeira, 2018. Disponível em: <https://www.bcb.gov.br/htms/estabilidade/2018 10/refPub.pdf >. Acesso em: 4 out. 2019 .

CHIAVENATO, Idalberto. Gestão de Pessoas. São Paulo: Editora Campus Elsevier, 2004.

COHEN, Marlene. Como escalar montanhas de salto alto? Exercendo no poder feminino. São Paulo: Saraiva, 2009. 
CROCHIK, J. L. Aspectos que permitem a segregação na escola pública. CONSELHO REGIONAL DE PSICOLOGIA. São Paulo: Casa do Psicólogo, 1996.

FRANKEL, Lois P. Mulheres lideram melhor que homens. São Paulo: Gente. 2007.

GIL, Antonio Carlos. Como elaborar projetos de pesquisa. São Paulo: Editora Atlas, 2002.

GRANT THORTON. Woman in Business, 08 mar. 2017. Disponível em:

<https://www.grantthornton.com.br/insights/articles-and-publications/women-in-business-

2017/>. Acesso em: 12 ago, 2019.

GUIA DOS BANCOS RESPONSÁVEIS. Nos bancos, mulheres estudam mais, ganham menos e têm menos promoções. 03 mar. 2019. Disponível em: $<$ https://guiadosbancosresponsaveis.org.br/de-olho-nos-bancos/2019/nos-bancosmulheres-estudam-mais-ganham-menos-e-t\%C3\%AAm-menospromo\%C3\%A7\%C3\%B5es/

GUIA DOS BANCOS RESPONSÁVEIS. Qual papel as mulheres ocupam perante o sistema financeiro nacional, 8 mar. 2019. Disponível em: $<$ https://guiadosbancosresponsaveis.org.br/de-olho-nos-bancos/2019/qual-papel-asmulheres-ocupam-perante-o-sistema-financeiro-nacional/>. Acesso em: 12 ago, 2019.

HARRISON-WALKER, L. J. Strategic positioning of nations as brands. Journal of International Business Research, v.10, n.2, p. 135- 147, 2011.

HRYNIEWICZ, L. G. C.; VIANNA, M. A. Mulheres em posição de liderança: obstáculos e expectativas de gênero em cargos gerenciais. Cad. EBAPE.BR, Rio de Janeiro, v. 16, n. 3, 2018 .

IBGE. Indicadores IBGE: pesquisa nacional por amostra de domicílios contínua. Rio de Janeiro. Coordenação de Trabalho e Rendimento. 
IBGE. Quantidade de homens e mulheres. 2018. Disponível em: $<$ https://educa.ibge.gov.br/jovens/conheca-o-brasil/populacao/18320-quantidade-dehomens-e-mulheres.html>. Acesso em: 22 de ago. 2019.

ITAÚ. Relatório anual de sustentabilidade. 2017. Disponível em: <https://www.itau.com.br/relatorio-anual/sustentabilidade/>. Acesso em: 3 out. 2019.

KAMLOT, D.; DUBEUX, V. J. C.; CASTRO, L. N. V. Comportamento de consumidores de instituições financeiras antes e após um processo de fusão. Revista de Economia e Administração, Rio de Janeiro, v. 10, n. 4, p. 540-563, 2011.

KOTLER, P.; KELLER, K. L. Administração de Marketing. São Paulo: Pearson, 2012.

LAROUCHE, Janice et RYAN, Regina. Estratégias para mulheres no trabalho. São Paulo: Makron, McGraw-Hill, 1991.

LODEN, Marilyn. Liderança feminina: como ter sucesso nos negócios sendo você mesma. São Bernardo do Campo, SP: Bandeirante, 1988.

MOSCOVICI, Serge. A representação social da psicanálise. Rio de Janeiro: Zahar, 1978.

OIT. Participação das mulheres no mercado de trabalho ainda é menor que dos homens. Nações Unidas, 07 mar. 2018. Disponível em: <https://nacoesunidas.org/oit-participacaodas-mulheres-no-mercado-de-trabalho-ainda-e-menor-que-dos-homens/>. Acesso em: 11 set. 2019.

RECCHIA, J.G.; BROUGH, G.; MOURA, A. Perfil da Executiva Brasileira. Caliper Estratégias Humanas do Brasil, 2007. Disponível em $<\underline{\text { http://www.calipermedia.calipercorp.com/whitepapers/br/perfil-da-executiva-brasileira.pdf }}$ >. Acesso em: 10 ago, 2019. 
RODRIGUES, Stephane Carvalho; SILVA, Gleiciane Rosa. A liderança feminina no mercado de trabalho. Vol. 1. Revista digital de Administração Faciplac, 2015.

RIES, Al.; TRIOUT, Jack. Posicionamento: a Batalha por sua mente. São Paulo: M.Books, 2009.

SANTOS, E. M. A busca da diversidade no setor financeiro, 2008. Disponível em: $<$ http://www.fazendogenero.ufsc.br/8/sts/ST1/Eliana Maria dos Santos 01.pdf $>$. Acesso em: 12 set, 2019.

SILVA, P. D. S.; RODRIGUES, F. D.; NETO, A. V.; DE QUEIROZ, S. N. Mulheres Bancárias no Mercado de Trabalho Brasileiro. Revista da ABET, Rio Grande do Norte, v. 17, n. 1, p. 135-53, 2018.

SOLOMON, M. R. O Comportamento do Consumidor: comprando, possuindo e sendo. Porto Alegre: Bookman, 2007.

VERGARA, S.C. Projetos e Relatórios de Pesquisa em Administração. São Paulo: Atlas, 2000.

VILAS-BÔAS, R. M. Ações Afirmativas e o Princípio da Igualdade. Rio de Janeiro: América Jurídica, 2003. 


\section{Anexo 1- Questionário da pesquisa de campo (versão feminina)}

Olá,

Primeiramente gostaria de agradecer a sua participação.

O questionário é completamente anônimo e não demorará mais de 5 minutos para ser respondido. Tenha em mente que não existem respostas certas ou erradas, apenas opiniões. Além disso, vale ressaltar que após responder uma pergunta, não será possível alterar a sua resposta.

Tal questionário foi elaborado para estudar as percepções dos consumidores do mercado bancário no Brasil.

Se você já respondeu uma pesquisa similar a essa, por favor não responda novamente.

1) Qual a sua idade?
( ) Menor de 18 anos
( ) Entre 18 e 24 anos
( ) Entre 25 e 31
() Entre 32 e 38
() Entre 39 e 45
() Entre 46 e 52
( ) Acima de 52 anos

2) Qual o seu gênero?
() Feminino
( ) Masculino
( ) Prefiro Não dizer

3) Qual o seu grau de escolaridade?
( ) Ensino Fundamental completo
() Ensino Fundamental incompleto
( ) Ensino Médio completo
( ) Ensino Médio incompleto
( ) Ensino Superior completo
( ) Ensino Superior incompleto
( ) Pós graduação completa
( ) Pós graduação incompleta

4) Qual a sua faixa de renda familiar?
( ) Até 2 salários mínimos (Até $\mathrm{R} \$ 1.576,00$ )
( ) 2 a 4 salários mínimos (De $R \$ 1.576,01$ a $R \$ 3.152,00$ )
( ) 4 a 10 salário mínimos (De $\mathrm{R} \$ 3.152,01$ a $\mathrm{R} \$ 7.880,00$ )
( ) 10 a 20 salários mínimos (De $\mathrm{R} \$ 7.880,01$ a $\mathrm{R} \$ 15.760,00$ )
( ) Acima de 20 salários mínimos ( $\mathrm{R} \$ 15.760,01$ ou mais) 
5) De qual banco abaixo você é consumidor?
( ) Banco do Brasil
( ) Caixa Econômica Federal
( ) Itaú Unibanco
( ) Bradesco
( ) Santander
( ) BTG Pactual
() Safra
() Banco Inter
() Nubank
( ) Outro

Leia a reportagem abaixo e em seguida responda as questões de acordo com sua opinião e grau de concordância:

Às $16 \mathrm{~h} 03$, dessa sexta-feira $(18 / 10)$ as ações do Banco INVEST caíram 21,60\%. Segundo um levantamento feito ontem, nos últimos dois anos o banco obteve a maior queda do retorno percentual da ação em dólares entre todos os 45 bancos do levantamento.

A economista Silvia Carvalho (46 anos), diretora do banco há 5 anos, se pronunciou dizendo que a diretoria vem se esforçando para melhorar os resultados obtidos, uma vez que o cenário externo é complexo e extremamente instável, porém ainda não foi alcançado o sucesso desejado.

6) Qual grau de sucesso você acredita que essa diretora possui? Em uma escala de 1 (significando "nenhum") a 10 (significando "muito"), escolha a alternativa.

$$
\mid-1-2-3--4-5-6-7-8-9--10
$$

7) Na sua opinião, qual é a responsabilidade dessa profissional pelos resultados da organização? Em uma escala de 1 (significando "nenhuma") a 10 (significando "muita"), escolha a alternativa.

$$
\mid-1-2-3--4-5-6-7-8-9--10
$$

8) A profissional possui capacidade para ocupar o cargo.
( ) Discordo totalmente
( ) Discordo parcialmente
( ) Não concordo, nem discordo
( ) Concordo Parcialmente
( ) Concordo totalmente

9) A diretora sabe avaliar as consequências de suas decisões estratégicas.

( ) Discordo totalmente 

( ) Discordo parcialmente
( ) Não concordo, nem discordo
( ) Concordo Parcialmente
( ) Concordo totalmente

10) Por ser mulher, a diretora provavelmente possui uma postura mais:
( ) Sábia
() Racional
() Coerente
() Frágil
( ) Incoerente
( ) Emocional
( ) Não possuo opinião formada

11) No dia a dia dessa profissional, ela encontra dificuldades especificamente por ser mulher.
( ) Discordo totalmente
( ) Discordo parcialmente
( ) Não concordo, nem discordo
( ) Concordo Parcialmente
( ) Concordo totalmente

12) O fato de ser mulher influencia nas ações a serem tomadas e na postura da profissional.
( ) Discordo totalmente
() Discordo parcialmente
( ) Não concordo, nem discordo
( ) Concordo Parcialmente
( ) Concordo totalmente

13) Sendo um homem ao ocupar o mesmo cargo, o resultado alcançado seria melhor.
( ) Discordo totalmente
( ) Discordo parcialmente
( ) Não concordo, nem discordo
( ) Concordo Parcialmente
( ) Concordo totalmente

\section{Anexo 2- Questionário da pesquisa de campo (versão masculina)}

Olá,

Primeiramente gostaria de agradecer a sua participação.

O questionário é completamente anônimo e não demorará mais de 5 minutos para ser respondido. Tenha em mente que não existem respostas certas ou erradas, apenas opiniões. Além disso, vale ressaltar que após responder uma pergunta, não será possível alterar a sua resposta. 
Tal questionário foi elaborado para estudar as percepções dos consumidores do mercado bancário no Brasil.

Se você já respondeu uma pesquisa similar a essa, por favor não responda novamente.

1) Qual a sua idade?
() Menor de 18 anos
( ) Entre 18 e 24 anos
( ) Entre 25 e 31
() Entre 32 e 38
() Entre 39 e 45
() Entre 46 e 52
( ) Acima de 52 anos

2) Qual o seu gênero?
() Feminino
() Masculino
( ) Prefiro Não dizer

3) Qual o seu grau de escolaridade?
( ) Ensino Fundamental completo
( ) Ensino Fundamental incompleto
( ) Ensino Médio completo
() Ensino Médio incompleto
( ) Ensino Superior completo
( ) Ensino Superior incompleto
( ) Pós graduação completa
( ) Pós graduação incompleta

4) Qual a sua faixa de renda familiar?

( ) Até 2 salários mínimos (Até $\mathrm{R} \$ 1.576,00$ )

( ) 2 a 4 salários mínimos (De $R \$ 1.576,01$ a $R \$ 3.152,00$ )

( ) 4 a 10 salário mínimos (De $R \$ 3.152,01$ a $R \$ 7.880,00$ )

( ) 10 a 20 salários mínimos (De $\mathrm{R} \$ 7.880,01$ a $\mathrm{R} \$ 15.760,00$ )

( ) Acima de 20 salários mínimos ( $R \$ 15.760,01$ ou mais)

5) De qual banco abaixo você é consumidor?
( ) Banco do Brasil
() Caixa Econômica Federal
( ) Itaú Unibanco
() Bradesco
( ) Santander
( ) BTG Pactual
() Safra
() Banco Inter
( ) Nubank
() Outro 
Leia a reportagem abaixo e em seguida responda as questões de acordo com sua opinião e grau de concordância:

Às $16 \mathrm{~h} 03$, dessa sexta-feira $(18 / 10)$ as ações do Banco INVEST caíram 21,60\%. Segundo um levantamento feito ontem, nos últimos dois anos o banco obteve a maior queda do retorno percentual da ação em dólares entre todos os 45 bancos do levantamento.

O economista Silvio Carvalho (46 anos), diretor do banco há 5 anos, se pronunciou dizendo que a diretoria vem se esforçando para melhorar os resultados obtidos, uma vez que o cenário externo é complexo e extremamente instável, porém ainda não foi alcançado o sucesso desejado.

6) Qual grau de sucesso você acredita que o diretor do banco possui? Em uma escala de 1 (significando "nenhum") a 10 (significando "muito"), escolha a alternativa.

$$
\mid-1-2-3--4-5-6-7-8-9-10
$$

7) Na sua opinião, qual é a responsabilidade desse profissional pelos resultados da organização? Em uma escala de 1 (significando "nenhum") a 10 (significando "muito"), escolha a alternativa.

$\mid-1-2-3--4-5-6-7-8-9-10$

8) O profissional possui capacidade para ocupar o cargo.
( ) Discordo totalmente
( ) Discordo parcialmente
( ) Não concordo, nem discordo
( ) Concordo Parcialmente
( ) Concordo totalmente

9) O diretor sabe avaliar as consequências de suas decisões estratégicas.
( ) Discordo totalmente
( ) Discordo parcialmente
( ) Não concordo, nem discordo
( ) Concordo Parcialmente
( ) Concordo totalmente

10) Por ser homem, o diretor provavelmente possui uma postura mais:
( ) Sábia
() Racional
() Coerente
() Frágil
( ) Incoerente 

( ) Emocional
( ) Não possuo opinião formada

11) No dia a dia desse profissional, ele encontra dificuldades especificamente por ser homem.
( ) Discordo totalmente
( ) Discordo parcialmente
( ) Não concordo, nem discordo
( ) Concordo Parcialmente
( ) Concordo totalmente

12) $O$ fato de ser homem influencia nas ações a serem tomadas e na postura do profissional.
( ) Discordo totalmente
() Discordo parcialmente
( ) Não concordo, nem discordo
( ) Concordo Parcialmente
( ) Concordo totalmente

13) Sendo uma mulher ao ocupar o mesmo cargo, o resultado alcançado seria melhor.
( ) Discordo totalmente
( ) Discordo parcialmente
( ) Não concordo, nem discordo
( ) Concordo Parcialmente
( ) Concordo totalmente 